NUMBER 59 / MARCH 2013

\title{
EUROPEAN
}

\section{RESPIRATORY monograph}

CLINICAL HANDBOOKS FOR THE RESPIRATORY PROFESSIONAL

Edited by Klaus F. Rabe, Jadwiga A. Wedzicha and Emiel F.M. Wouters

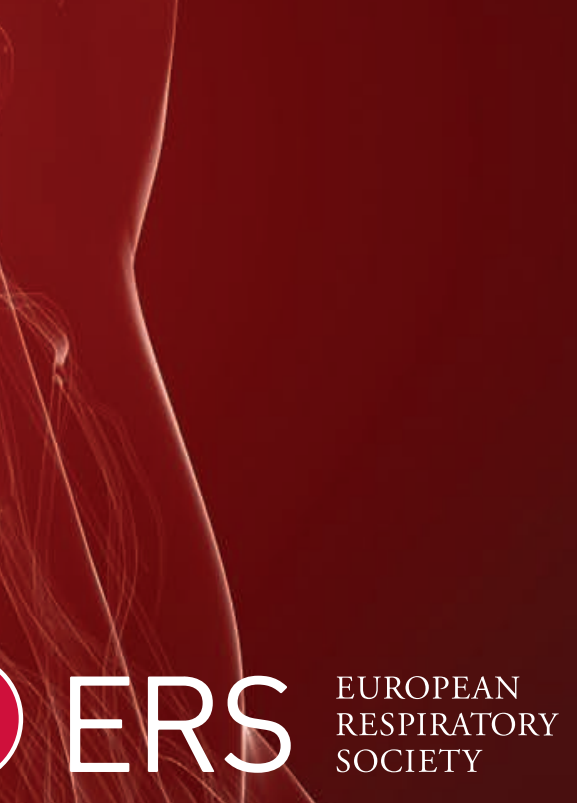

gvery breath counts 
Purchased by ,

From: European Respiratory Society Publications (reader.ersjournals.com) 
Published by European Respiratory Society @2013

March 2013

Print ISBN: 978-1-84984-032-3

Online ISBN: 978-1-84984-033-0

Print ISSN: $1025-448 x$

Online ISSN: 2075-6674

Printed by Page Bros Ltd, Norwich, UK

Managing Editor: Rachel White European Respiratory Society 442 Glossop Road, Sheffield, S10 2PX, UK

Tel: 441142672860

E-mail: Monograph@ersj.org.uk

All material is copyright to European Respiratory Society. It may not be reproduced in any way including electronic means without the express permission of the company.

Statements in the volume reflect the views of the authors, and not necessarily those of the European Respiratory Society, editors or publishers.
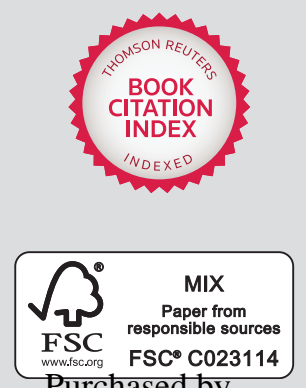

Purchased by,

From: European Respiratory Society Publications (reader.ersjournals.com)

\section{COPD and Comorbidity}

\author{
Edited by \\ Klaus F. Rabe, Jadwiga A. Wedzicha and \\ Emiel F.M. Wouters
}

\section{Editor in Chief Tobias Welte}

This book is one in a series of European Respiratory Monographs. Each individual issue provides a comprehensive overview of one specific clinical area of respiratory health, communicating information about the most advanced techniques and systems required for its investigation. It provides factual and useful scientific detail, drawing on specific case studies and looking into the diagnosis and management of individual patients. Previously published titles in this series are listed at the back of this Monograph. 
Purchased by ,

From: European Respiratory Society Publications (reader.ersjournals.com) 
Preface

Guest Editors vii

Introduction

1. Prevalence of COPD and comorbidity Shambhu Aryal, Enrique Diaz-Guzman and David M. Mannino

2. COPD: inflammatory mechanisms and systemic consequences Peter J. Barnes

3. Assessment of cardiovascular comorbidity John D. Maclay and William MacNee

4. Diagnosis and management of heart failure in COPD Frans $H$. Rutten

5. Infection and comorbidity Richa Singh, Alexander J. Mackay and Jadwiga A. Wedzicha

6. Malnutrition and obesity in COPD Erica P.A. Rutten, Emiel F.M. Wouters and Frits M.E. Franssen

7. Osteoporosis in COPD

Elisabeth A.P.M. Romme, Frank W.J.M. Smeenk, Emiel F.M. Wouters and Erica P.A. Rutten

8. Gastro-oesophageal reflux disease and COPD Anant R.C. Patel and John R. Hurst

9. Metabolic syndrome and diabetes mellitus in COPD

Claire E. Wells and Emma H. Baker

10. Obstructive sleep apnoea and COPD

Walter T. McNicholas and Ruth Lee

11. Management of depression and anxiety in COPD Paul A. Cafarella, Tanja W. Effing, Christopher Barton, David Ahmed and Peter Anthony Frith

12. Managing skeletal muscle dysfunction in COPD Thierry Troosters, Wim Janssens and Marc Decramer

Purchased by ,

From: European Respiratory Society Publications (reader.ersjournals.com) 
13. Lung cancer in COPD

Georgia Hardavella and Stephen Spiro

14. Pulmonary hypertension in COPD

Jordanna Hostler, A. Whitney Brown, John Sherner, Christopher S. King and Steven D. Nathan

15. COPD and thrombosis

Peter K. MacCallum

16. Comorbidities in current COPD guidelines

Per Sigvald Bakke

CME credit application form

\begin{tabular}{l|l|l|l|l}
$\mathbf{C}$ & $\mathbf{O}$ & $\mathbf{P}$ & $\mathbf{E}$ & commitiee on publication ethics
\end{tabular}

This journal is a member of and subscribes to the principles of the Committee on Publication Ethics.

Purchased by,

From: European Respiratory Society Publications (reader.ersjournals.com) 


\section{Preface}

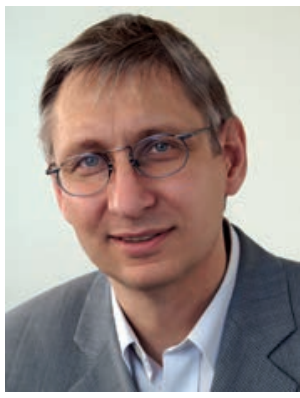

Chronic obstructive pulmonary disease (COPD) is the most common

respiratory disease worldwide and has a significant impact on mortality, morbidity and healthcare costs. The incidence of COPD is strongly correlated with age. As such, increasing life expectancy in industrialised societies combined with the fast growth of companies in Asia and Africa mean it is highly likely that COPD will be the most significant chronic disease of all in the future.

For decades, COPD has been viewed as a lung-specific disease. Studies on the effectiveness of therapeutic interventions have focused on lung function and lung function-associated parameters. However, with the increasing number of elderly COPD patients, it has become apparent that many of these patients are also affected by a number of other chronic diseases, such as diabetes, cardiovascular disease, and psychiatric and neurological alterations. COPD is an independent risk factor for the prognosis of these diseases, and, likewise, they influence the prognosis of COPD itself. In recent years, there has been controversial debate about the responsibility of the COPD underlying chronic inflammation in the pathogenesis of other diseases; this has not been definitely confirmed. Factors such as genetic susceptibility and the environment may also explain the frequent co-occurrence of diseases of different organ systems. Regardless of the outcome of this debate, it seems clear that in the future, the prognosis of COPD can no longer be detected using respiratory parameters alone. The influence of therapeutic interventions on the course of comorbidities is not known yet and may be an area of major interest for further study.

COPD and the role of COPD in other diseases clearly demonstrates that respiratory medicine stands at the centre of internal medicine. This leads to several important implications for the future. A department of pneumology has to be established in every general hospital. Diagnostic and therapeutic aspects of the comorbidities also have to be included in pulmonary education and training programmes.

I want to congratulate the Guest Editors Klaus F. Rabe, Jadwiga A. Wedzicha and Emiel F.M. Wouters for the tremendous work they have done in bringing together this excellent, cutting-edge issue of the European Respiratory Monograph (ERM). Readers from many different areas will find this issue useful in their daily work, and it will be of particular interest to both medical doctors and respiratory physicians. I am sure they will find that this issue of the ERM provides them with useful guidance on the future of basic and clinical research, and much more.

Eur Respir Monogr 2013; 59: v. Copyright ERS. DOI: 10.1183/1025448x.10000613. Print ISBN: 978-1-84984-032-3. Online ISBN: 978-1-84984-033-0. Print ISSN: 1025-448x. Online ISSN: 2075-6674.

Purchased by , 
Purchased by ,

From: European Respiratory Society Publications (reader.ersjournals.com) 


\section{Guest Editors}

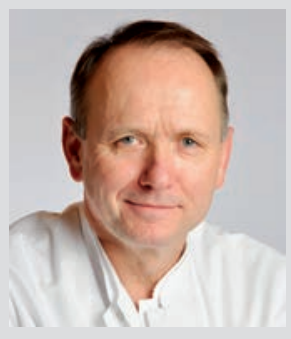

Klaus F. Rabe

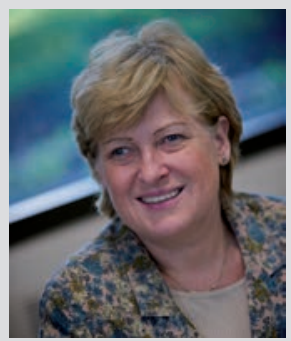

Jadwiga A. Wedzicha

Eur Respir Monogr 2013; 59: vii-viii. Copyright ERS 2013.

DOI: $10.1183 / 1025448 x \cdot 10000913$

Print ISBN: 978-1-84984-032-3

Online ISBN: 978-1-84984-033-0

Print ISSN: $1025-448 \mathrm{x}$

Purchansed by ,

From: European Respiratory Society Publications (reader.ersjournals.com)
Klaus F. Rabe is Professor of Pulmonary Medicine at the University of Kiel (Kiel, Germany) and Director of the Department of Pneumology at Lung Clinic Grosshansdorf (Grosshansdorf, Germany). He has been active in various fields of respiratory medicine worldwide, predominantly asthma, COPD and lung cancer.

Professor Rabe took his final exams in medicine at the University of Hamburg (Hamburg, Germany) in 1983 and his clinical education began at Marienkrankenhaus Hamburg (1983-1987) where he then spent time working at Universitätskrankenhaus Eppendorf (University of Hamburg) within the intensive care and endoscopic units. In 1988, Professor Rabe worked in the pulmonary division of Krankenhaus Grosshansdorf, the Centre for Pneumology and Thoracic Surgery (Grosshandsdorf), and then in 1989, he worked in clinical research in the Department of Thoracic Medicine of the National Heart and Lung Institute (London, UK). In 1998, Professor Rabe was nominated Professor of Medicine at the University of Leiden (Leiden, the Netherlands) where he was also appointed as the Chairman of Pulmonology, and later, in 2007, as the Chairman of Medicine. In 2010, he moved back to Germany into his current position.

Professor Rabe has served on various editorial boards, was the first European Associate Editor of the American Journal of Respiratory and Critical Care Medicine and was co-Chief Editor of the European Respiratory Journal. His current scientific interests are related to large clinical trials in COPD and asthma, the mechanisms of airway inflammation, and the endoscopic staging of lung cancer. Professor Rabe has served on the boards of the Global Initiative for Asthma (GINA) and the Global Initiative of Chronic Obstructive Lung Disease (GOLD), and is a member of the German and Dutch Chest Societies, the British Pharmacological Society, and the American Thoracic Society (ATS). He is the immediate Past-President of the European Respiratory Society (ERS).

Jadwiga A. Wedzicha is Professor of Respiratory Medicine at the UCL Medical School and the Royal Free Hospital (both London, UK). She qualified from Somerville College (Oxford University, Oxford, UK) and St Bartholomew's Hospital Medical College (University of London, London).

Professor Wedzicha has a major interest in the causes, mechanisms, impact and prevention of COPD exacerbations and in the role of bacterial and viral infection in COPD exacerbation. She directs an active research group into COPD exacerbations and has published extensively on this topic.

Professor Wedzicha chairs the English Department of Health Home Oxygen Clinical User Group, and was a member of the Guideline Development Group for the revision of the NICE COPD Guidelines. She is also a member of the Programme Board for the English COPD National Clinical Strategy.

Professor Wedzicha was Editor-in-Chief of Thorax from 2002 to 2010, and is a member of the BioMed Central and the American Journal of Respiratory and Critical Care Medicine advisory boards. She is also a member of the editorial boards of a number of international journals. Until 2012, she was Guidelines Director for the European Respiratory Society (ERS) and is currently the Publications Committee Chair of ERS Publications. 


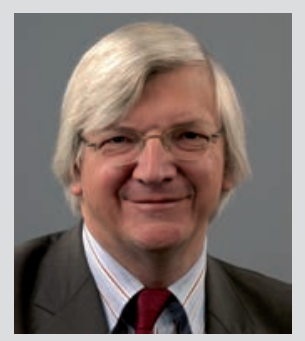

Emiel F.M. Wouters

Professor Emiel F.M. Wouters studied medicine at the Catholic University of Leuven (Leuven, Belgium), where he graduated in 1978. He was trained in internal medicine at the Annadal Hospital Maastricht (Maastricht, the Netherlands) and the University Hospital Leuven (Leuven). In 1981, he started his residency at the Department of Pulmonology of the University Hospital Maastricht (Maastricht) and was registered as a pulmonologist in July 1984. He received his PhD for his thesis, entitled "Bronchial response in COPD measured by forced oscillation technique", at the same university in 1987. After his appointment to Associate Professor of Pulmonology in 1988, he became Full Professor and Chairman of the Department of Respiratory Medicine of the University Hospital Maastricht in 1992 and Chairman of the Medical Board of the Asthma Centre Hornerheide (Horn, the Netherlands). He is currently involved in research into inflammation and multi-component pathology of COPD.

Professor Wouters has acted as Chair of the Scientific Board of the Dutch Asthma Foundation, as well as Chair of the Rehabilitation and Chronic Care Group of the European Respiratory Society (ERS). He was Chief Editor of the European Respiratory Monograph (ERM) until 2005. Professor Wouters is the Director of the Centre for Chronic Diseases of the Maastricht University Medical Centre (Maastricht, the Netherlands), the Chief Executive Officer of the Centre for Integrated Rehabilitation of Chronic Organ Failure (CIRO Horn) and the research leader of the COPD Centre of Excellence of the NUTRIM (Nutrition, Toxicology and Metabolism) Research School (Maastricht University Medical Centre). He is also visiting professor at the University of Vermont (Burlington, VT, USA).

Professor Wouters fulfils different memberships of the scientific boards and task forces of respiratory medicine, and has published as (co)author of more than 500 papers in scientific journals, largely related to COPD.

Purchased by , 


\title{
Introduction
}

\author{
Klaus F. Rabe ${ }^{\star \#}$, Jadwiga A. Wedzicha and Emiel F.M. Wouters ${ }^{+}$
}

\begin{abstract}
${ }^{\star}$ Dept of Internal Medicine, Christian Albrechts University Kiel, Kiel. ${ }^{\#}$ Lung Clinic Grosshansdorf, Grosshansdorf, Germany. ${ }^{~ " C e n t r e ~ f o r ~ R e s p i r a t o r y ~}$ Medicine, University College London, London, UK. ${ }^{+}$Maastricht University Medical Center, Maastricht University, Maastricht, the Netherlands.

Correspondence: J.A. Wedzicha, Centre for Respiratory Medicine, University College London, Rowland Hill Street, London, NW3 2PF, UK. Email: w.wedzicha@ucl.ac.uk
\end{abstract}

OPD is a common and progressive chronic inflammatory condition that is responsible for a large amount of morbidity and mortality globally, and affects millions of people worldwide. It is now recognised that COPD is a heterogeneous disease and that the severity of the airflow obstruction, as determined by the forced expiratory volume in 1 second (FEV1), is not the best determinant of the severity of COPD and its impacts. Thus, severity of this disease is now determined by the combination of symptoms, future risk that is mainly related to exacerbation frequency, and FEV1 stage.

COPD is not only associated with airway inflammation but also with considerable systemic inflammation, though the precise relationship between the airway and systemic inflammatory processes in COPD remains to be elucidated. It has been proposed that this systemic inflammation is responsible for the considerable comorbidity that is seen in COPD. Thus, COPD is a disease that reaches far outside the lung, and comorbidity is found in all stages of COPD even in patients with mild and moderate COPD by FEV1 stage. Cigarette smoking is the main risk factor for COPD and it is also a risk factor for other major diseases, such as cancer and cardiovascular disease, which are also more common with increasing age. These comorbidities will have an influence on the severity of COPD, and need to be addressed in severity and impact scores for COPD. Management of comorbidities will also have an effect on outcome in COPD; there is, for example, emerging data that COPD patients with cardiovascular risk who are treated with beta blockers have a better outcome, particularly when admitted to hospital with COPD exacerbations. Similarly, bronchodilator and anti-inflammatory therapy in COPD may impact on the degree of comorbidity, although historically, COPD patients with comorbidities have been excluded from clinical trials.

This issue of European Respiratory Monograph (ERM) aims to address the inter-relationships of COPD and comorbidity, a very wide and diverse topic, as can be seen from the contents list. There has been considerable recent emphasis on the study of comorbidity in COPD and a number of new studies have been published. Thus, the chapters are up to date, well referenced and written by a team of international experts with a clinical focus.

The ERM starts with a description of the epidemiology of comorbidity as applied to COPD, and this is followed by a description of inflammatory mechanisms of COPD and how these relate to comorbidity. The chapters that follow discuss cardiovascular disease in COPD; there has been much interest in cardiovascular comorbidity as it accounts for a considerable amount of mortality in COPD. However, cardiovascular disease is often unrecognised in COPD and it is important to understand its impact both during exacerbations and when patients are stable. Heart failure is common in an ageing population and thus frequently coexists in COPD with overlap of symptoms. Pulmonary hypertension affects the prognosis of COPD but may often be undetected. Airway infection contributes to the mechanisms of both stable COPD and exacerbations, and it is known that airway infection may be associated with increased cardiovascular events and haematological abnormalities. Pneumonia is an important comorbidity in COPD, with recent data

Eur Respir Monogr 2013; 59: ix-x. Printed in UK - all rights reserved, Copyright ERS 2013. European Respiratory Monograph; DOI: 10.1183/1025448x.10001213. Print ISBN: 978-1-84984-032-3. Online ISBN: 978-1-84984-033-0. Print ISSN: 1025-448x. Online ISSN: 2075-6674.

Purchased by,

From: European Respiratory Society Publications (reader.ersjournals.com) 
suggesting that it may be precipitated by inhaled corticosteroid therapy. COPD patients are current or previous smokers and are at increased risk of lung cancer.

Metabolic conditions are also important comorbidities, and this issue of the ERM includes chapters that address obesity in malnutrition in COPD, obstructive sleep apnoea, and osteoporosis, which is one of the most common comorbidities in COPD and is potentiated by the effect of inactivity and corticosteroids. Diabetes affects both stable and exacerbated COPD, and improved diabetic control may benefit exacerbation outcome. Associations have been shown between exacerbation frequency and gastro-oesophageal reflux that will be discussed in this issue of the ERM, though the actual mechanisms of reflux in COPD are not clear and may relate to the mechanical effects of hyperinflation. Inactivity is related to prognosis in COPD and skeletal muscle dysfunction needs to be assessed and targeted. Psychological disease (anxiety and depression in particular) is often present in COPD and must be targeted; it is particularly common in patients who have a higher exacerbation risk.

Thus, clinical programmes for the management of COPD patients must not only treat airways disease but should also assess and manage the associated comorbidities. This will make COPD management a much more complex, long-term process in the future, requiring multi-disciplinary teams with relevant specialist interests. It is essential that clinical trials include and, wherever possible, specifically target patients with comorbidities, as respiratory therapies may improve comorbidities. At the same time, any adverse effect of therapies on comorbidities in an increasingly ageing population must be recognised early and where patients require multiple pharmacological approaches, optimal adherence to therapy must be ensured. Current therapies for COPD are actually relatively limited and thus it is possible that therapies targeting comorbidities may have a significant impact on health status and mortality in COPD. Further research and evidence is required to inform future guidelines on the relationship of complex comorbidity in COPD.

We hope that you will find this issue of the ERM a useful resource that aids understanding of the role of comorbidity in COPD and the way in which comorbidity potentially influences disease management. This book will be of benefit to a wide number of healthcare professionals, including clinicians, nurses and allied healthcare professionals, but it will also be of interest to those specialising in the management of comorbidities, such as cardiologists and gastroenterologists. The chapters are up to date and well referenced, and will stimulate novel ideas for research and inspire healthcare professionals in training. We are very grateful to all the authors who have contributed excellent chapters on such an important and yet relatively poorly understood and researched topic. 